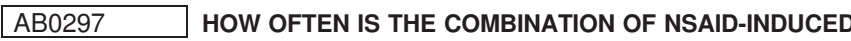
LESIONS OF THE UPPER AND LOWER GI TRACT?

Anna Balabantseva, Andrey Karateev. V. A. Nasonova Research Institute of Rheumatology, Moscow, Russian Federation

Background: Non-steroidal anti-inflammatory drugs (NSAIDs) can damage all parts of the gastrointestinal tract (GIT). However, the frequency of the combination of lesions in different parts of the gastrointestinal tract has not been studied.

Objectives: To assess the frequency of the combination of NSAIDinduced lesions of the upper Gl tract, small and large intestine.

Methods: The study group consisted of 112 patients with rheumatic diseases $(62.5 \%$ of women, $56.2+14.6$ years), who regularly took NSAIDs. All patients underwent endoscopy of the upper GI tract and colon. Capsule endoscopy was performed in 35 patients with signs of NSAIDgastropathy.

Results: NSAID-gastropathy (erosions and/or gastric or duodenum ulcers) were detected in $43.8 \%$, NSAID enteropathy (hemorrhages, erosions and ulcers of the small intestine) in $68.6 \%$, NSAIDs-colopathy (hemorrhages, erosions and ulcers of the colon) - $14.3 \%$ patients. The combination of NSAID-gastro- and colonopathy was detected in $28.6 \%$ of patients (odds ratio $12.2,95 \% \mathrm{Cl} 2.619-56.84$ ), the combination of NSAID-gastro, enteroand colopathy - in 10 patients $(20.4 \%$ of the number of patients with NSAID-gastropathy). There was a significant risk association for the development of NSAID-induced lesions in all parts of the Gl tract with a diagnosis of spondyloarthritis, the presence of abdominal pain, small intestine bacterial overgrowth, as well as in the polymorphism of the CYP2C19 gene (CYP2C19 * $17 * 1 / * 17$ allele).

Conclusion: The combined NSAID-induced damage of various parts of the $\mathrm{Gl}$ tract is a frequent and serious pathology requiring complex diagnostics and the combined use of prophylactic agents with a different mechanism of action.

Disclosure of Interests: None declared

DOI: 10.1136/annrheumdis-2019-eular.6153

\section{AB0298 COMPLICATIONS OF RHEUMATOID ARTHRITIS AND ALLIED DISORDERS- A STATISTICAL COMORBIDITY STUDY OF 234 AUTOPSY PATIENTS}

Miklós Bély ${ }^{1}$, Ágnes Apáthy ${ }^{2} .{ }^{1}$ Hospital of the Order of the Brothers Saint John of God in Budapest, Department of Pathology, Budapest, Hungary; ${ }^{2}$ St. Margaret Clinic, Budapest, Department of Rheumatology, Budapest, Hungary

Background: Complications of rheumatoid arthritis (RA) may modify the clinical course and symptoms of allied disorders leading to missed diagnosis or late recognition of associated diseases.

Objectives: The aim of this study was to determine the possible role of classic complications of RA: systemic autoimmune vasculitis (AV), AA amyloidosis (AAa), lethal cardiac insufficiency (Cl) caused by endo-, myoor pancarditis, furthermore lethal septic infection (SI) on prevalence and mortality of coexistent associated diseases: atherosclerosis (Ath), hypertension (HT), type 2 diabetes mellitus (DM) and tuberculosis ( $\mathbf{T b}$ ) with miliary dissemination $(\mathbf{m T b})$.

Methods: 234 non- selected autopsy patients with RA were studied. RA was confirmed clinically according to the criteria of the ARA.

The presence of $\mathbf{A V}, \mathbf{A A a}, \mathbf{C l}$ and $\mathbf{S I}$ was determined at autopsy and confirmed by a detailed review of extensive histological material. The prevalence and mortality of associated diseases Ath, HT, DM, Tb or mTb were analyzed retrospectively, reviewing the clinical and pathological reports.

The link between AV, AAa, $\mathbf{C l}$ or SI and Ath, HT, DM, Tb or mTb was analyzed by $\left(\chi^{2}\right)$ test

Results: RA was complicated by AV in $43(18.4 \%)$, by AAa in 48 $(20.5 \%)$, by $\mathrm{Cl}$ with lethal outcome in $15(6.4 \%)$, and by lethal $\mathrm{SI}$ in 33 (14.1\%) of 234 patients.

RA associated with severe Ath in $106(\mathbf{4 5 . 3} \%)$, with HT in 41 (17.5\%), with DM in $41(17.5 \%)$, and with Tb in $28(11.9 \%)$, with active $\mathrm{mTb}$ in $9(3.8 \%)$ of 234 patients.

As a basic disease Ath led to death in $61(26.1 \%$ of 106$)$, HT in 2 $(0.9 \%$ of 41$)$, DM in none $(0 \%$ of 41$)$, and Tb with $\mathrm{mTb}$ in $3(1.3 \%$ of 28) of 234 patients. Tb without miliary dissemination was not lethal in our patient population.

The statistical links ("p" values of significance) between complications of RA and prevalence or mortality of allied disorders are summarized in Table.

(*asterisk indicates a negative value of associations' coefficient with inverse relationship).

\begin{tabular}{|c|c|c|c|c|}
\hline $\begin{array}{l}\text { Complications of } \\
\text { RA }\end{array}$ & $\begin{array}{c}A V n=43 \text { of } \\
234\end{array}$ & $\begin{array}{c}\text { AAa } n=48 \text { of } \\
234\end{array}$ & $\begin{array}{c}\mathrm{Cl} n=15 \text { of } \\
234\end{array}$ & SI $n=33$ of 234 \\
\hline \multicolumn{5}{|l|}{$\begin{array}{l}\text { Allied disorders in } \\
\text { RA }\end{array}$} \\
\hline Ath $\mathrm{n}=106$ of 234 & $\begin{array}{c}\chi^{2}=6.43^{\star} \\
p<0.01\end{array}$ & $\begin{array}{c}\chi^{2}=10.04^{\star} \\
p<0.001\end{array}$ & $\begin{array}{c}\chi^{2}=0.92^{*} \\
p<0.33\end{array}$ & $\begin{array}{c}\chi^{2}=5.03^{\star} \\
p<0.02\end{array}$ \\
\hline $\begin{array}{l}\text { Ath lethal } n=61 \text { of } \\
106\end{array}$ & $\begin{array}{c}\chi^{2}=15.92^{\star}, \\
p<0.00\end{array}$ & $\begin{array}{c}\chi^{2}=11.04^{\star} \\
p<0.00\end{array}$ & $\begin{array}{c}\chi^{2}=4.29^{\star}, \\
p<0.03\end{array}$ & $\begin{array}{c}\chi^{2}=12.01^{*} \\
\mathrm{p}<0.00\end{array}$ \\
\hline HT 41 of 234 & $\begin{array}{c}\chi^{2}=3.30^{\star} \\
p<0.07\end{array}$ & $\chi^{2}=0.03^{*}, p<0.86$ & $\begin{array}{c}\chi^{2}=0.00^{*} \\
p<0.92\end{array}$ & $\begin{array}{c}\chi^{2}=1.27^{*} \\
p<0.25\end{array}$ \\
\hline HT lethal $n=2$ of 41 & $\begin{array}{c}\chi^{2}=0.05^{*} \\
p<0.80\end{array}$ & $\chi^{2}=0.02, p<0.87$ & $\begin{array}{c}\chi^{2}=1.16^{*} \\
p<0.28\end{array}$ & $\begin{array}{c}\chi^{2}=0.19^{*} \\
p<0.65\end{array}$ \\
\hline DM 41 of 234 & $\chi^{2}=0.04, p<0.8$ & $\chi^{2}=0.84^{*}, p<0.35$ & $\begin{array}{c}\chi^{2}=0.92 \\
p<0.33\end{array}$ & $\begin{array}{c}\chi^{2}=0.01 \\
p<0.91\end{array}$ \\
\hline Tb 28 of 234 & $\begin{array}{c}\chi^{2}=4.02 \\
p<0.04\end{array}$ & $\chi^{2}=2.61^{\star}, p<0.10$ & $\begin{array}{l}\chi^{2}=0.33 \\
p<0.56\end{array}$ & $\begin{array}{l}\chi^{2}=0.37 \\
p<0.54\end{array}$ \\
\hline Tb lethal $n=3$ of 28 & $\begin{array}{c}\chi^{2}=0.00^{\star} \\
p<0.93\end{array}$ & $\chi^{2}=0.02^{\star}, p<0.86$ & $\begin{array}{c}\chi^{2}=0.53^{*} \\
p<0.46\end{array}$ & $\begin{array}{c}\chi^{2}=0.01^{*} \\
p<0.89\end{array}$ \\
\hline mTb 9 of 28 & $\begin{array}{c}\chi^{2}=4.24 \\
p<0.03\end{array}$ & $\chi^{2}=0.08, p<0.77$ & $\begin{array}{c}\chi^{2}=0.01 \\
p<0.91\end{array}$ & $\begin{array}{c}\chi^{2}=0.05 \\
p<0.82\end{array}$ \\
\hline $\mathrm{mTb}$ lethal $n=3$ of 9 & $\begin{array}{c}\chi^{2}=0.00^{*} \\
p<0.93\end{array}$ & $\chi^{2}=0.02^{*}, p<0.86$ & $\begin{array}{c}\chi^{2}=0.53^{*} \\
p<0.46\end{array}$ & $\begin{array}{c}\chi^{2}=0.01^{*} \\
p<0.89\end{array}$ \\
\hline
\end{tabular}

Conclusion: The inverse correlations between $\mathbf{A V}, \mathbf{A A a}, \mathbf{C l}, \mathbf{S I}$ and $\mathbf{A t h}$ HT, DM, Tb or $\mathbf{m T b}$ indicate that the prevalence and mortality of allied disorders were not influenced basically by the complications of RA.

The consequently inverse and (in most cases) significant correlations between prevalence of $\mathbf{A V}, \mathbf{A A a}, \mathbf{C l}, \mathbf{S I}$ and the prevalence and mortality of Ath show that these are are independent entities in RA. The AV $\mathbf{A A a}, \mathbf{C l}$ and $\mathbf{S I}$ are the most important complications of RA, and are characterize severe forms of disease, mostly involving younger patients, with an earlier onset (without pronounced Ath); while Ath is basically an age dependent phenomenon, characteristically present in RA patients with advanced age. RA patients with Ath may represent a special group of RA, characterized by lower incidence of $\mathbf{A V}, \mathbf{A A a}, \mathbf{C l}$ or $\mathbf{S I}$, and a better prognosis.

The positive and significant relations $\mathbf{A V}$ to $\mathbf{T b}$ or $\mathbf{m T b}$ suggest an increased risk of $\mathrm{Tb}$, e.g. the presence of $\mathbf{A V}$ may promote $\mathbf{T b}$ or endogenous exacerbation and miliary dissemination of $\mathbf{T b}$.

Disclosure of Interests: None declared

DOI: 10.1136/annrheumdis-2019-eular.1273

\section{AB0299 COXITIS DURING CHRONIC INFLAMMATORY RHEUMATISM}

Hedia Ben Abla, Sonia Rekik, Samia Jammali, Soumaya Boussaid, Hela Sahli, Elhem Cheour, Mohamed Elleuch. la rabta, tunis, Tunisia

Background: The occurrence of coxitis in chronic inflammatory rheumatism is a prognostic factor of great importance given the functional repercussions of the involvement of the coxofemoral joint.

Objectives: The aim of this work is to evaluate the prevalence of this lesion in chronic inflammatory rheumatism (PR/JIA/SpA) and to describe the evolution of this disorder according to the pathology.

Methods: Eighty-two patients with chronic inflammatory rheumatism were enrolled. These patients were followed by the rheumatology department rabta since 2004 until March 2018. The clinical demographics, activity scores, treatment background (all our patients in this series were under biotherapy) and the need PTH were identified.

Results: The eighty-two patients were distributed as follows: $36.58 \%$ ( $n=$ 30) patients with RA, 36.58\% (n=30) SpA and $26.83(n=22)$ JIA The average age was 48.3 years, 47.6 years and 32.17 years. For the rheumatoid arthritis population $26.67 \%(n=8)$ of the patients had a cox ite of which $62.5 \%(n=5)$ was bilateral and $37.5 \%(n=3)$ unilateral. The mean time to discovery of coxite was 11.7 years and the evolution was in $50 \%(\mathrm{n}=4)$ to worsening requiring in 3 cases a bilateral PTH and a case of synoviorthesis.

In the SpA group, 23.33\% ( $\mathrm{n}=7)$ of patients had coxitis, of which $57.14 \%(n=4)$ were bilateral and $32.86 \%(n=3)$ unilateral. The aver age time to discovery was 8.22 years. PTH was performed in $71.43 \%$ (n $=5$ ) of patients.

For the JIA population, $45.45 \%(n=10)$ of the patients had a coxite of which $80 \%(n=8)$ was bilateral and $20 \%$ unilateral. The average time to discovery of this lesion was 14 years, with $60 \%$ of cases progressing to an aggravation requiring $40 \%$ of the cases for synoviorthesis and $60 \%$ for PTH.

Conclusion: SpA is the most common chronic inflammatory rheumatism with cxo-femoral involvement with the most pejorative evolution despite the biological treatment 